\title{
Geomorfologia e feições ilustradas: contribuições para a formação docente
}

\section{Geomorphology and illustrated features: contributions for training teachers}

\author{
Hikaro Kayo de Brito Nunes* $\bowtie$ (D) \\ Universidade do Estado do Amazonas, Tefé, Amazonas, Brasil \\ *E-mail para correspondência: hikarokayo2@hotmail.com
}

Recebido (Received): 01/02/2020

Aceito (Accepted): 13/05/2020

\begin{abstract}
Resumo: Constantemente há necessidade de utilização de recursos didáticos não-convencionais e de metodologias ativas no processo de formação de professores. Diante disso e associado com o campo de atuação e de possibilidades de interpretação, a Geografia possibilita aos acadêmicos/alunos conhecer e experienciar distintos fatos e fenômenos em escalas temporal e espacial. Assim, o presente estudo tem como objetivo contribuir com a discussão em torno do ensino de Geomorfologia (nos cursos de formação de professores de Geografia) pautado na criatividade materializada em desenhos que proporcionam um entendimento da caracterização geomorfológica e dos processos atuantes em áreas do Piauí e Ceará (Brasil). Cabe ressaltar que a produção dos desenhos foi subsidiada pela realização de duas atividades de campo, correspondendo às disciplinas de Geomorfologia e Geomorfologia do Quaternário. Ao longo das atividades e da produção dos desenhos, a utilização de elementos como linha, volume, luz, sombra, cor, textura e escala contribuiu para a tomada de conhecimento da percepção e de como os alunos enxergavam determinado processo, ancorados pela discussão teórica anterior. Com base nisso, a tríade apresentada, conhecimento científico - prática docente -criatividade (visão dos alunos), possibilitou que os desenhos atingissem função importante junto aos processos e significados expressos, bem como no despertar para a prática professoral.
\end{abstract}

Palavras-chaves: Formação de professores de Geografia; Geomorfologia; Desenhos; Atividades de campo.

Abstract: Constantly no need to use unconventional and active methodologies teaching resources in the teacher training process. In view of this and associated with playing field and possibilities of interpretation, Geography enables scholars/students know and experience different facts and phenomena in temporal and spatial scales. Thus, the present study aims to contribute to the discussion on the teaching Geomorphology (in Geography teacher training courses) based on creativity materialized in drawings that provide an understanding of the geomorphological characterization and of the processes acting in areas of Piaui and Ceará (Brazil). Note that the production of the drawings was supported by performing two field corresponding to activities and disciplines geomorphology and geomorphology quaternary. Throughout the activities and preparation of the drawings, the use of elements such as line, volume, light/shadow, color, texture and scale contributed to the perception of knowledge-making and how students could see certain process, anchored by the previous theoretical discussion. With this base, the triad presented knowledge teaching - scientific creativity - practical (students's views) enabled the drawings reached important function with the processes and meanings expressed, as well as the awakening to professorial practice.

Keywords: Geography teacher training; Geomorphology; Drawings; Field activities.

\section{Introdução}

Ao longo dos anos, a inserção de recursos didáticos não-convencionais e de metodologias ativas em sala de aula tornou-se ferramenta fundamental. Contudo, a inclusão dessas estratégias junto à prática docente nos cursos de formação de professores ainda estivera incipiente, se comparada à aplicação para a educação básica, notadamente associada às alterações na educação brasileira (ARAÚJO e TROLEIS, 2015; GATTI, 2017). 
Afinal de contas, como nós, docentes de cursos de Licenciatura em Geografia, preparamos nossos alunos a desenvolverem atividades dinâmicas, criativas e participativas na educação básica, se, muitas vezes, não o fazemos? Como possibilitar práticas e vivências que possam contribuir de forma significativa na formação docente, como a utilização/confecção/produção de desenhos?

Autores como Campos (2012), Santana e Braga (2013), Cruz e Aguiar (2014), Cortizo, Ferreira e Farias (2017) e Kaercher e Bohrer (2018) afirmam que o docente é um espelho para o licenciando construir sua prática professoral, daí a necessidade de possibilitar debates, questionamentos e problematizações em torno dos mecanismos responsáveis pelo processo de formação de professores de Geografia, com o intuito, principalmente, de se compreender as complexidades resultantes do saber e fazer docente em sua totalidade.

O presente estudo trata de reflexões oriundas da prática docente durante 2 períodos letivos nas disciplinas de "Geomorfologia do Quaternário" e "Geomorfologia" de cursos de Licenciatura em Geografia de duas universidades localizadas no Nordeste Brasileiro, uma estadual e outra federal. Com base nisso, o texto que se segue apresenta como pretensão, relacionar possibilidades entre o conhecimento científico da Geografia (no caso a Geomorfologia), a prática docente (tendo em vista a utilização de recursos didáticos nãoconvencionais e metodologias ativas) e a visão dos alunos (essa sustentada no conceito de Paisagem para, com base nessa, representar, em forma de desenhos, distintos elementos do modelado terrestre).

Frente à questão anunciada, cabe considerar a sustentação teórica de Perrenoud (1999; 2000), no que concerne ao uso dos termos habilidades e competência; de Ausubel (1982) e Novak e Gowin (1999), acerca da aprendizagem significativa e da utilização de grafismos, lógicas e hierarquização de ideias; e de Cabanellas (1976), Senai (1984) e Fiori (2011) no tangente aos itens básicos para o planejamento e execução de representações por meio do desenho.

O conhecimento geomorfológico teve distintos centros de discussão que permearam o seu objeto de análise, levando em consideração notadamente o contexto social e as limitações científicas à época, tendo em vista que, com o passar dos anos, fora atribuído de inúmeros conceitos, abordagens, escalas (temporal e espacial) e de articulações, tendo como destaque o elemento relevo, ora como aspecto necessário para a análise ambiental, ora como fator indispensável para o planejamento e ordenamento (ABREU, 2003; SUERTEGARAY, 2018; NUNES, 2019).

No contexto da paisagem, necessária para a representação em desenhos, este conceito apresenta-se no presente estudo como capaz de sintetizar as relações entre sociedade/homem e natureza/meio e expressa como resultado da variedade da superfície terrestre (CONTI, 2014). Nesse sentido, a paisagem é, conforme Ab'Saber (2003), Passos (2013) e Neves e Salinas (2017), um conceito associado a um determinado período histórico, face a distintas facetas, e que possui forte relação com o método geossistêmico enquanto sustentação para diagnósticos e prognósticos ambientais.

As leituras aqui expressas possibilitam a construção das práticas e reflexões, notadamente no que diz respeito aos conceitos de relevo, escala e processos, mesmo que o foco esteja pautado nas habilidades e competências materializadas em desenhos que possibilitam um entendimento sobre a visão do aluno diante de determinada feição (ou processo) geomorfológica.

Face o exposto, e alicerçado na formação de professores de Geografia, este estudo tem como objetivo contribuir com a discussão em torno do ensino de Geomorfologia (nos cursos de formação de professores de Geografia) pautado na criatividade materializada em desenhos que proporcionam um entendimento da caracterização geomorfológica e dos processos atuantes em áreas do Piauí e Ceará (Brasil).

Não é pretensão, no entanto, servir como um manual ou um guia de aplicação da utilização de desenhos como recurso didático no processo de formação de professores de Geografia, tendo em vista as múltiplas formas de se trabalhar a Geomorfologia, ou de representar pontos negativos ou positivos desse processo. $\mathrm{O}$ texto constitui-se, assim, de reflexões na prática docente no ensino superior, com o intuito ainda de juntar-se a importantes referências, como Lopes e Ponthuschka (2009; 2015), Morais e Moraes (2010), Afonso (2013), Souza e Valadão (2015), Bezerra e Melo (2018), Souza (2018), Castellar (2018) e Venturi (2018).

\section{Materiais e métodos}

Metodologicamente, este estudo se caracteriza como Estudo de Caso envolto à prática professoral junto às disciplinas de "Geomorfologia" e "Geomorfologia do Quaternário" em duas universidades públicas dos estados do Piauí e Maranhão durante 2 períodos letivos (entre 2018 e 2019), pautado principalmente na inserção de desenhos como estratégia de ensino na formação de professores de Geografia. 
Sobre o método adotado, conforme Yin (2010), este é encarado como uma importante estratégia para investigações no âmbito das ciências humanas, permitindo, ao pesquisador, um aprofundamento em relação ao fato ou fenômeno estudado além do "olho nu", favorecendo, ainda, uma visão holística, seguindo, conforme Paré (2004) e Yin (2010), quatro etapas distintas: a) desenho do Estudo de Caso; b) condução; c) análise das evidências e d) escrita.

No contexto da formação docente e do currículo dos respectivos cursos de Geografia (licenciatura), as ementas das disciplinas são: i) Geomorfologia: Natureza e objeto da Geomorfologia; Teorias e metodologias utilizadas no estudo da Geomorfologia; Processos endógenos e exógenos na formação do relevo; Escalas espaciais no estudo geomorfológico; Domínios morfoclimáticos; Tipos e evolução do relevo nas unidades estruturais e formas recentes; A Geomorfologia no planejamento e na gestão ambiental; e ii) Geomorfologia do Quaternário: Importância da Geomorfologia do Quaternário; Geomorfologia Costeira; Geomorfologia Fluvial; Geomorfologia Cárstica; Processos atuantes em vertentes; Geomorfologia e o Tecnógeno.

Os referidos ementários contribuíram para o planejamento das disciplinas e das atividades de campo que subsidiaram a construção dos desenhos. Sobre atividades de campo, para Nunes, Sousa e Viana (2018, p. 14), "são importantes instrumentos metodológicos na formação de professores de Geografia, a julgar pela relação da construção da ação docente com a prática pedagógica", de modo que deve-se proporcionar aos alunos a vivência de práticas no meio em que estão inseridos, contribuindo para o desenvolvimento de habilidades, atitudes e saberes.

Quanto ao planejamento das atividades de campo, fundamentadas principalmente em Cavalcanti (2011) e Venturi (2011), salienta-se que as reflexões aqui apresentadas são oriundas de duas atividades distintas. A primeira, em Geomorfologia do Quaternário, ocorrida no primeiro semestre de 2018, teve como título "Estudo das características geoambientais e socioeconômicas de áreas do Nordeste Setentrional Brasileiro" e teve o seguinte objetivo no campo da disciplina: Compreender, em campo, a inter-relação dos aspectos geoambientais (geologia, geomorfologia, clima, hidrografia, pedologia e biogeografia) na formação das paisagens e na dinâmica ambiental local e regional, principalmente no tocante ao período Quaternário. Os destinos foram os municípios de Caxias e Timon (ambos no Maranhão), Piracuruca (Piauí) e Tianguá, Ubajara e Viçosa (todos no Ceará), envolvendo o Parque Nacional de Sete Cidades (PN7C) e o Parque Nacional de Ubajara.

Já a segunda atividade de campo, da disciplina de Geomorfologia, ocorrida no primeiro semestre de 2019, intitulada "Geomorfologia e ambiente na porção da Bacia Hidrográfica do Rio Poti no município de Teresina/PI", pretendia, à luz dos conhecimentos geográficos e geomorfológicos, proporcionar aos alunos a compreensão dos distintos elementos que atuam na gênese e dinâmica do modelado da área investigada, proporcionando conhecer a relevância dos fatos e processos geomorfológicos nos estudos ambientais, sua relação com o planejamento ambiental e ordenamento territorial. Esta atividade de campo percorreu parte considerável do município de Teresina tendo como recorte espacial a Bacia Hidrográfica do Rio Poti, envolvendo os seguintes pontos: Rodoanel de Teresina (toda a sua extensão); BR-316; Aterro Sanitário de Teresina e Bairro Bela Vista.

É válido ressaltar que ambas as atividades de campo tiveram 3 momentos distintos: o Pré-campo, com a elaboração do roteiro de observação, coleta de dados e definição/socialização dos objetivos; o Campo, que consistiu na verificação in loco dos fatos, fenômenos e processos geomorfológicos, considerando as particularidades de cada local subsidiado pelo preenchimento da planilha de campo; e o Pós-campo, que consistiu na socialização dos resultados para a turma e avaliação da atividade de campo. Nesses momentos, as atividades foram instrumentalizadas principalmente com mapas impressos, máquina fotográfica, filmadora, gravador de voz, GPS, pranchetas, papel A4, réguas, canetas e lápis de cor.

Quanto aos desenhos, ao fim de cada atividade de campo e das explanações decorrentes das mesmas, fora solicitado que os alunos, individualmente, em dupla ou em grupo, elaborassem uma representação de alguma paisagem relacionada com os objetivos anteriormente apresentados, como ilustrado por Johnson e Reynolds (2005), Courtot (2012) e Clopés e Serrano (2012). Cabe reforçar que toda a confecção dos desenhos foi feita em campo, de modo a possibilitar ainda aos alunos uma aproximação maior com o objeto a ser representado, bem como orientar a observação, registro, representação e análise das formas de relevo.

A explanação, também já realizada em sala de aula, sobre a construção dos desenhos, considerou, conforme Fiori (2011): a linha, tida como único elemento visual que não existe no plano concreto e que deve-se preocupar com as proporções dos elementos dispostos na paisagem; o volume, construído com base em três dimensões, o comprimento, a largura e a altura; luz e sombra, que possibilitam um realce intencional com base em tons claros e escuros; a cor, associada, neste caso, com as convenções; a textura, com 
experienciações ópticas; e a escala, que consiste na relação entre tamanho da área da ilustração e as informações a serem representadas.

Ao fim da construção dos desenhos, os mesmos foram socializados de modo que outros alunos puderam, a partir da observação e criatividade do colega, explicar os processos geomorfológicos representados. Para a confecção do mapa representando o percurso das atividades de campo, fez-se uso do programa QGis (versão 2.14, Essen) com adoção de arquivos vetoriais disponibilizados no sítio eletrônico do Instituto Brasileiro de Geografia e Estatística (IBGE).

\section{Resultados e discussão}

De modo a facilitar o entendimento dos leitores, os resultados, a seguir, serão subdivididos em: Atividade 01: Os desenhos, as paisagens e o estudo das características geoambientais e socioeconômicas de áreas do Nordeste Setentrional Brasileiro; e Atividade 02: Os desenhos, as paisagens e a Geomorfologia e ambiente na porção da Bacia Hidrográfica do Rio Poti no município de Teresina/PI, conforme Figura 1.

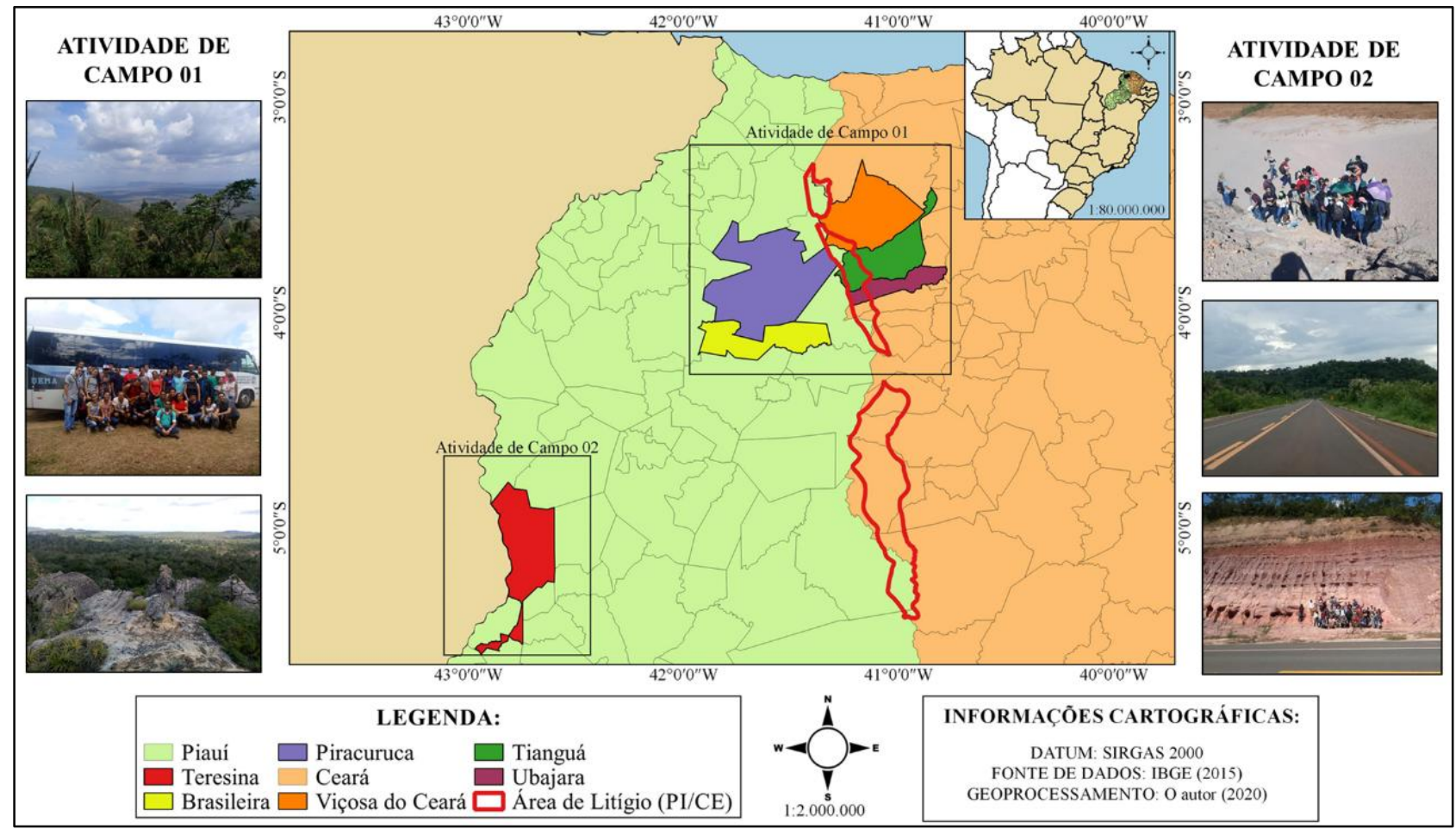

Figura 1: Mapa dos percursos das atividades de campo realizadas. Fonte: organizado pelo autor (2020)

Cada descrição contará com a seguinte sequência analítica e reflexiva: exposição das orientações em cada ponto; caracterização geomorfológica; exposição dos desenhos e análise dos desenhos considerando os itens básicos. Acrescenta-se ainda que, junto aos desenhos elaborados pelos alunos, há incorporada fotografia da área em ângulo mais próximo daquele representado. Tal recurso possibilitará ao leitor reflexões sobre as feições da paisagem que ora foram analisadas pelos alunos e que trará um entendimento sobre a percepção dos alunos sobre tal paisagem.

\subsection{Atividade 01: Os desenhos, as paisagens $e$ o estudo das características geoambientais $e$ socioeconômicas de áreas do Nordeste Setentrional Brasileiro}

No tangente à Serra da Ibiapaba (Noroeste do estado do Ceará), possui cotas altimétricas próximas à $920 \mathrm{~m}$, se caracterizando como uma serra úmida, também denominada "brejos de altitude", notadamente no que se refere às sua caracterização geoambiental (umidade e densas florestas) que contrastam com as superfícies que a margeia, principalmente caatinga, caracterizada pela ocorrência de intensos e prolongados períodos de estiagem.

Neste cenário, a exposição na referida área de estudo, aqui com destaque aos municípios de Tianguá, Ubajara e Viçosa, se deu com ênfase à importância, gênese e dinâmica geomorfológica da área, tendo em vista que tais feições do relevo, como afirma Moura-Fé (2017), apresentam características morfológicas comuns com outras serras úmidas cearenses e da região nordestina como um todo. No contexto geológico, a 
discussão se deu na relação litologia-relevo-tempo geológico, ao passo que a referida área está assentada nas formações geológicas de Ipu, Tianguá e Jaicós, todas pertencentes ao grupo Serra Grande (Paleozóico) que, em escala regional, ilustra uma superfície de cimeira (com caimento para Oeste), além de bordejar a Bacia Sedimentar do Parnaíba, em área litigiosa entre os estados do Piauí e Ceará.

Conforme IBGE (1995), a área possui as seguintes unidades de relevo: platôs (R2c); degraus litoestruturais (R4e) e planaltos mais rebaixados (R2b3 e R2b2), sustentados por rochas sedimentares da bacia do Parnaíba, perfazendo todo o limite ocidental do território cearense, na divisa com o estado do Piauí. Em direção à porção Leste (para o estado do Ceará), a unidade possui significativa feição escarpada (Figura 2) condicionada ao processo erosivo da borda chapada, expressando ainda a ocorrência de cornijas areníticas (Figura 3) com espessuras variadas e pacotes rochosos verticais formando relevo cuestiforme.

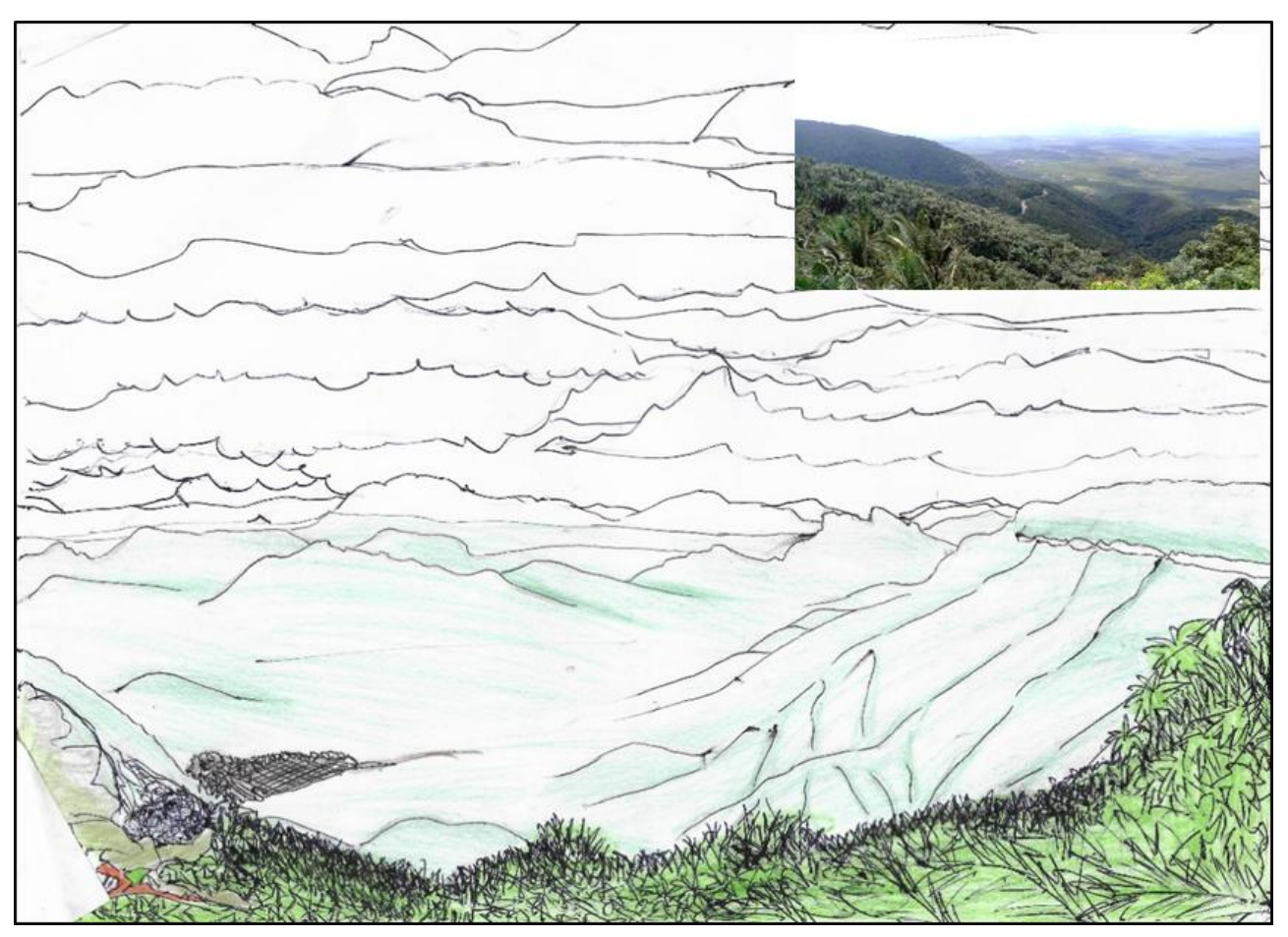

Figura 2: Representação de feição escarpada na borda Leste da Serra da Ibiapaba. Em primeiro plano, vegetação rasteira de área de lazer; ao lado direito, presença de escarpa; e, no lado esquerdo inferior, presença de núcleo urbano no sopé da escapa. Elaboração: A. A. Andrade.

Segundo IBGE (2009), as escarpas são tidas como desnível abrupto vinculado ao desgaste e recuo das vertentes, enquanto as cuestas são caracterizadas como formas de relevo assimétrico com desnível abrupto resultante de recuo erosivo de camadas sedimentares homoclinais, de resistências diferentes, apresentando frente escarpada (front) e reverso com fraca declividade.

Tanto na Figura 2 como na Figura 3, ilustra-se, entre vários processos e fenômenos geomorfológicos, a atuação do intemperismo (químico, físico e biológico), condicionando e determinando ainda a presença de canais fluviais, a diversidade das feições de relevo (em escalas micro e macro) e suas simetrias, a disposição dos depósitos de tálus e dos colúvios, bem como o contato com a depressão sertaneja.

Nota-se, com os referidos desenhos, a utilização de elementos importantes. Na Figura 2, por exemplo, as cores predominantes, no caso o branco (representando o céu, com a disposição de linhas ilustrando a nebulosidade do dia) e o verde (em três tonalidades, uma mais escura, exibindo a proximidade da vegetação; uma mais clara, evidenciando o papel da escala; e um degradê em uma tentativa de se ilustrar os depósitos de tálus e os colúvios, também com adoção de linhas). O volume, a luz e a sombra auxiliam na representação, na interpretação e na tomada de novos conhecimentos ou no reforço dos já existentes.

Na Figura 3 já há uma diversificação no uso das cores. Nesta, por convenção, o céu é retratado em azul e as nuvens em branco, além do verde da vegetação e na adoção da cor marrom para a representação da cornija. Os depósitos de tálus e colúvios, assim como na figura anterior também são representados. A presença de linhas, volumes, luz e sombra, escala tornam o entendimento mais fácil, bem como a adoção, nessa representação, de distintas texturas para representação da vegetação, no topo da serra, nos depósitos de colúvios, no sopé e na área em que está sendo realizada a visualização. 


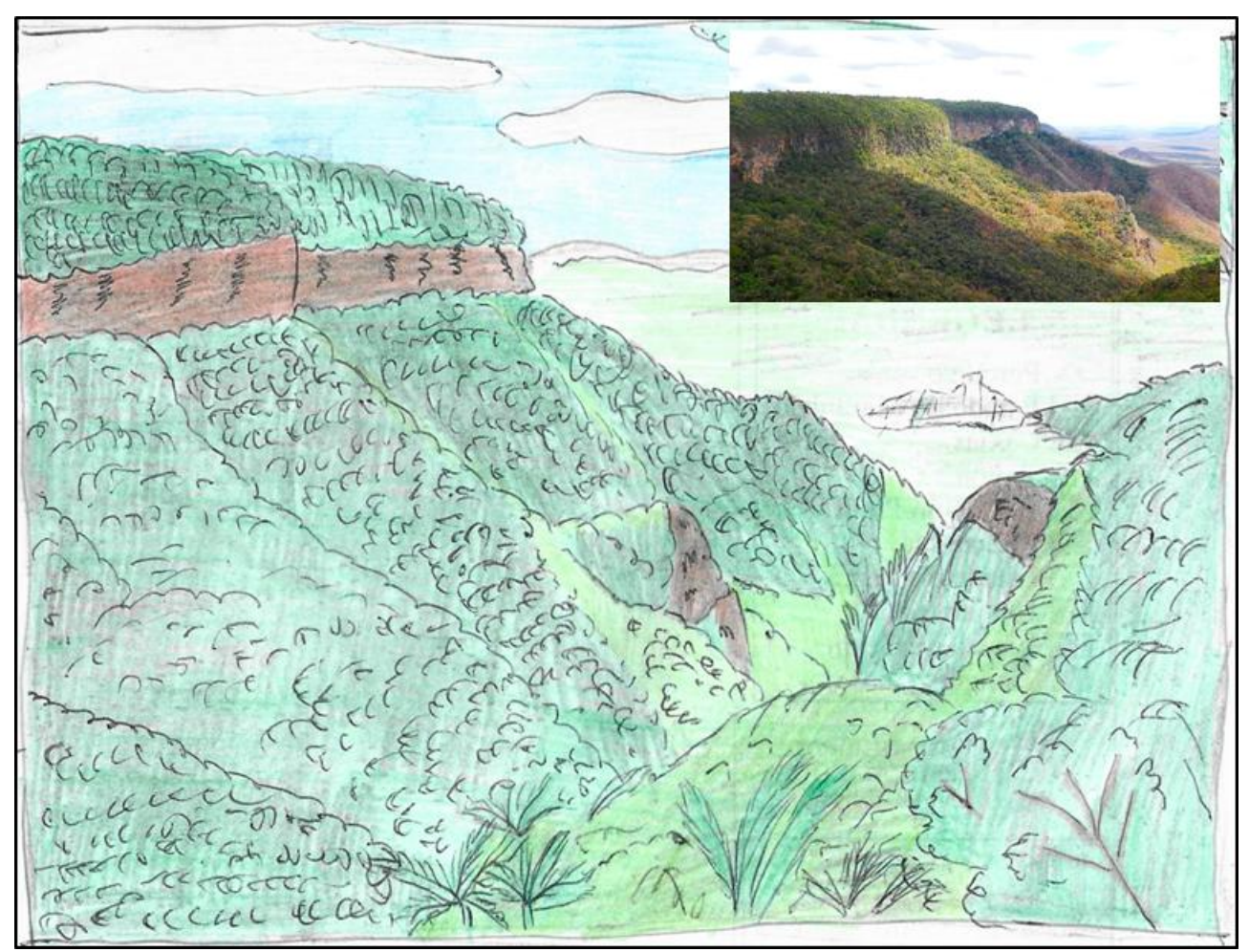

Figura 3: Representação de feição cornija arenítica em relevo cuestiforme e disposição dos depósitos de tálus e dos colúvios. Elaboração: J. A. Pereira e F. C. Pereira.

Prosseguindo com a atividade de campo e voltando pelo estado do Piauí (via BR-222), em aproximadamente $100 \mathrm{~km}$ iniciou-se outro momento da atividade, no caso a visita ao Parque Nacional de Sete Cidades (PN7C), localizado nos municípios de Piracuruca e Brasileira, inclusa na Bacia Hidrográfica do Rio Longá pertencente à Bacia Hidrográfica do Rio Parnaíba como eixo coletor final da drenagem do Piauí. A área está inserida na Bacia Sedimentar do Parnaíba e possui afloramentos de rochas que variam, entre o período Siluriano (439 milhões de anos) e Devoniano (409 milhões de anos), representando a Formação Cabeças (composta por arenito, conglomerado e siltito), possuidora de estratificação tabular face à deposição flúvio-deltáica (PRESS et al, 2006; SANTOS, 2018).

A presença significativa de feições areníticas expressam e condicionam o processo de modelagem das unidades do relevo presente no PN7C, ilustrando e exemplificando a origem de paisagens ruiniformes com presença, dentre outras unidades, de torres, alvéolos, pináculos e demoisseles. O surgimento deste relevo ruiniforme, portanto, como discutido junto aos alunos, deve-se à significativa atuação da erosão diferencial, ao passo da existência de exposição à ação das intempéries.

Neste caso, evidenciou-se adoção dos conceitos de Geodiversidade, Geoconservação e Geoturismo como subsídio para enriquecer a discussão, a julgar pela grande capacidade destes conhecimentos para a compreensão da formação e dinâmica do relevo local, como os geossítios apontados por Lopes (2011): Pedra da Tartaruga; Arco do Triunfo; Sítio Pequeno; Pedra do Americano; Biblioteca; Cidade Perdida; Pedra dos Canhões e Cachoeira do Riachão.

Durante o percurso no PN7C, um dos primeiros geossítios visitados e que serviu de base para a explicação foi a "Pedra da Tartaruga", um dos pontos mais conhecidos do Parque. As juntas poligonais (Figura 4) representam o processo de deposição, que, como afirma Bigarella et al. (1994), quando o pacote rochoso tem a capacidade de desidratação, este sofre compactação diferencial, criando, assim, um novo modelado. Cabe mencionar, ainda, o destaque que se deu à couraça ferruginosa, formada pelo processo de acumulação de sesquióxidos de ferro e alumínio.

A ação intempérica e formação de novas superfícies também é vista em outras áreas, com significativo interesse geomorfológico. Entre estes, destacam-se o "Arco do Triunfo" (Figura 5), tido como um alvéolo com significativo desenvolvimento; e a "Biblioteca" (Figura 6) onde há expressiva estratificação cruzada e presença de depósitos de canais estuarinos e fluviais ladeados por arenitos e siltitos. 


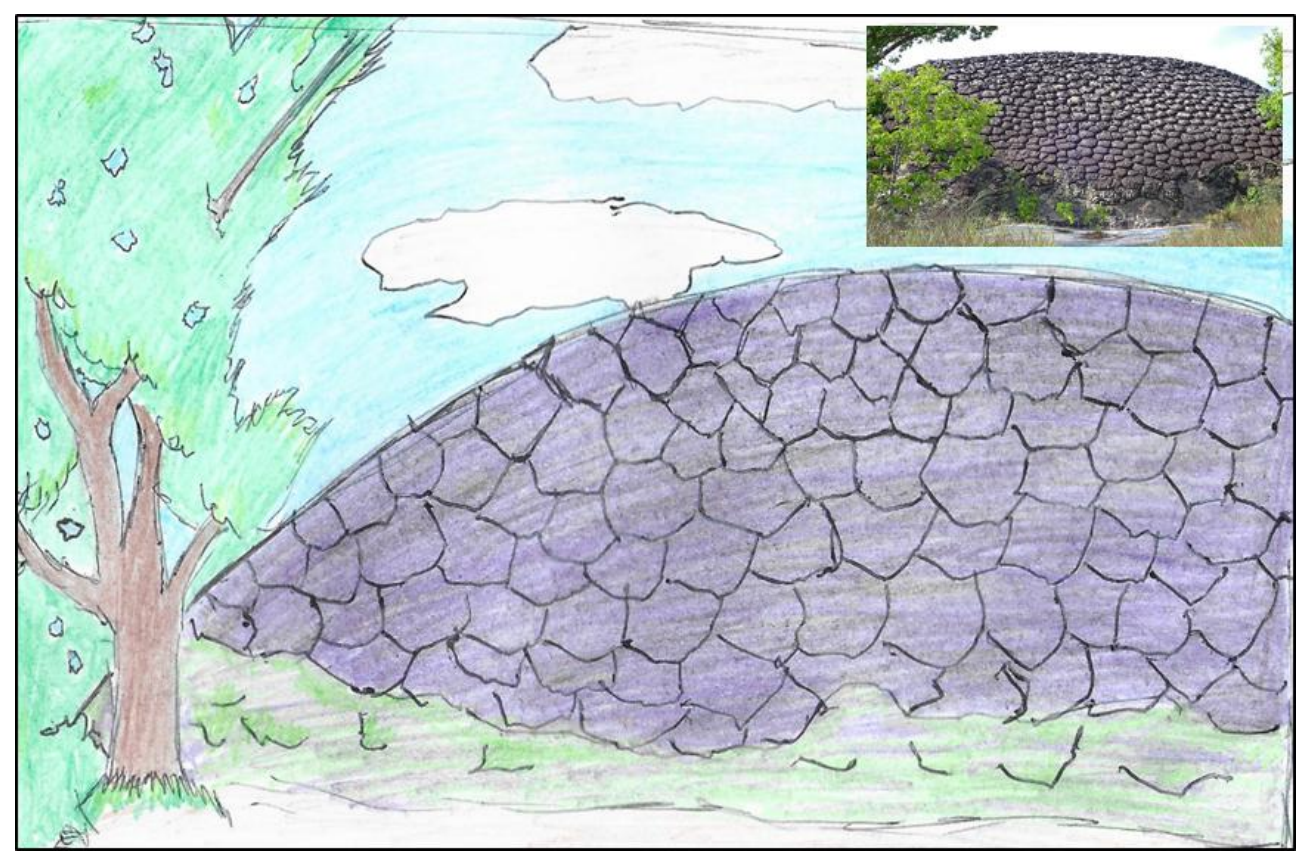

Figura 4: Representação do Geossítio identificado como "Casco de Tartaruga". Destaque para a formação de juntas poligonais e a couraça ferruginosa. Elaboração: J. A. Pereira e M. T. Santos.

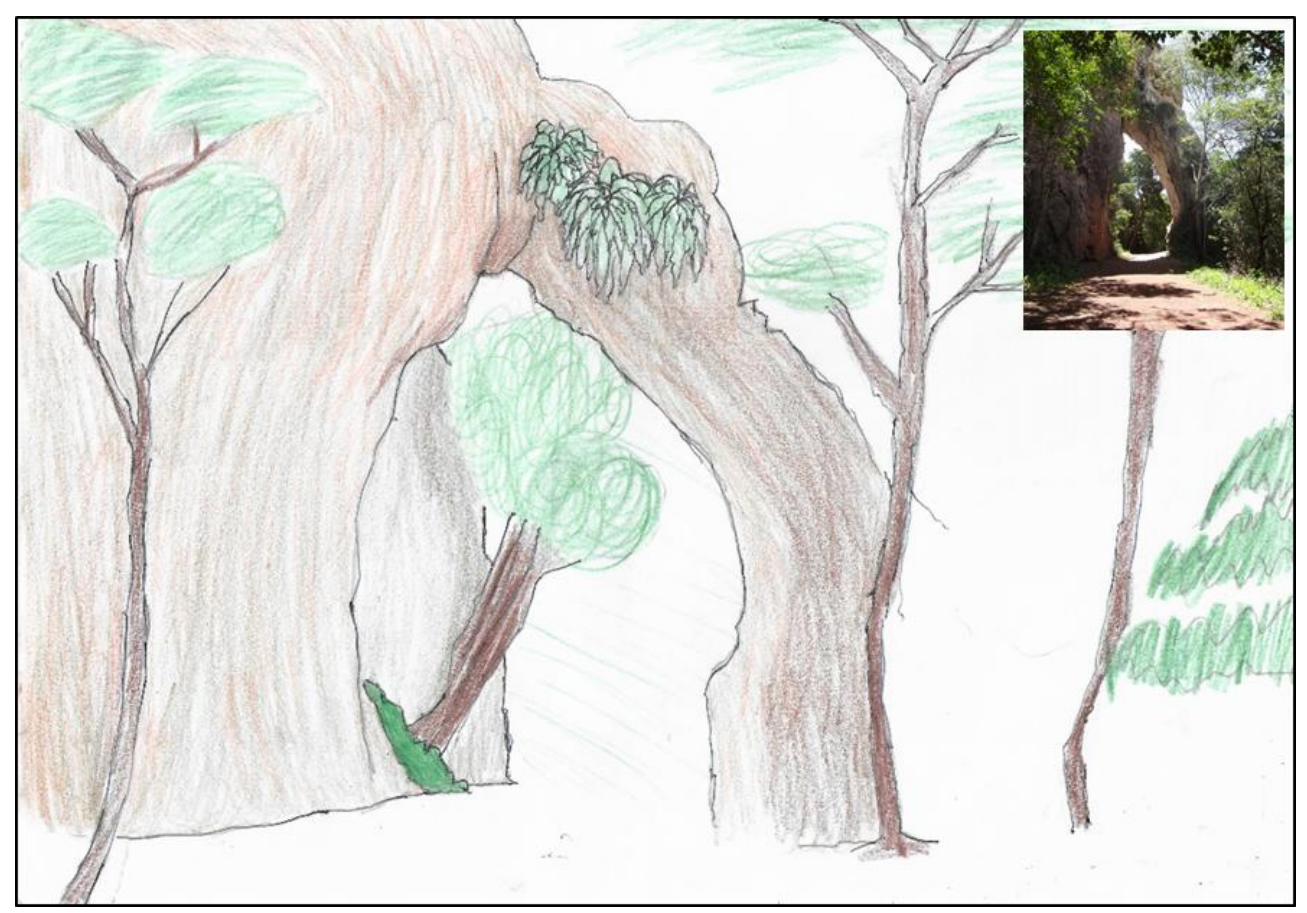

Figura 5: Representação do Geossítio "Arco do Triunfo". Destaque para os processos intempéricos atuantes na formação Cabeças. Elaboração: F. Silva e E. T. V. Santos.

$\mathrm{Na}$ Figura 4, as linhas representadas seguiram o formato das juntas poligonais que singularizam a referida feição desenhada, que fica ainda mais evidente pela adoção das cores: i) a vegetação (tons de verde e marrom); ii) o céu (representado pelo azul e o branco) e as próprias juntas poligonais, encarada e ilustrada com base na couraça ferruginosa. Já a Figura 5 é expressa também com a inclusão do volume, da luz e da sombra, principalmente para dar um sentido de profundidade em dois planos, um antes do arco e outro após. Na Figura 6, a diversificação das cores ilustra a presença e disposição dos arenitos e dos siltitos, bem como a atenção dada à sombra.

Aqui, faz-se uso do exposto por Morais (2014) de que o professor precisa, para realizar um bom trabalho, possuir uma formação consistente, conhecer as orientações curriculares e dispor de materiais didáticos; e que, além disso, o trato e inter-relação dessas necessidades tem a capacidade de despertar novos interesses e conhecimentos na turma, buscando, ainda, a somatização de recursos bem avaliados. 


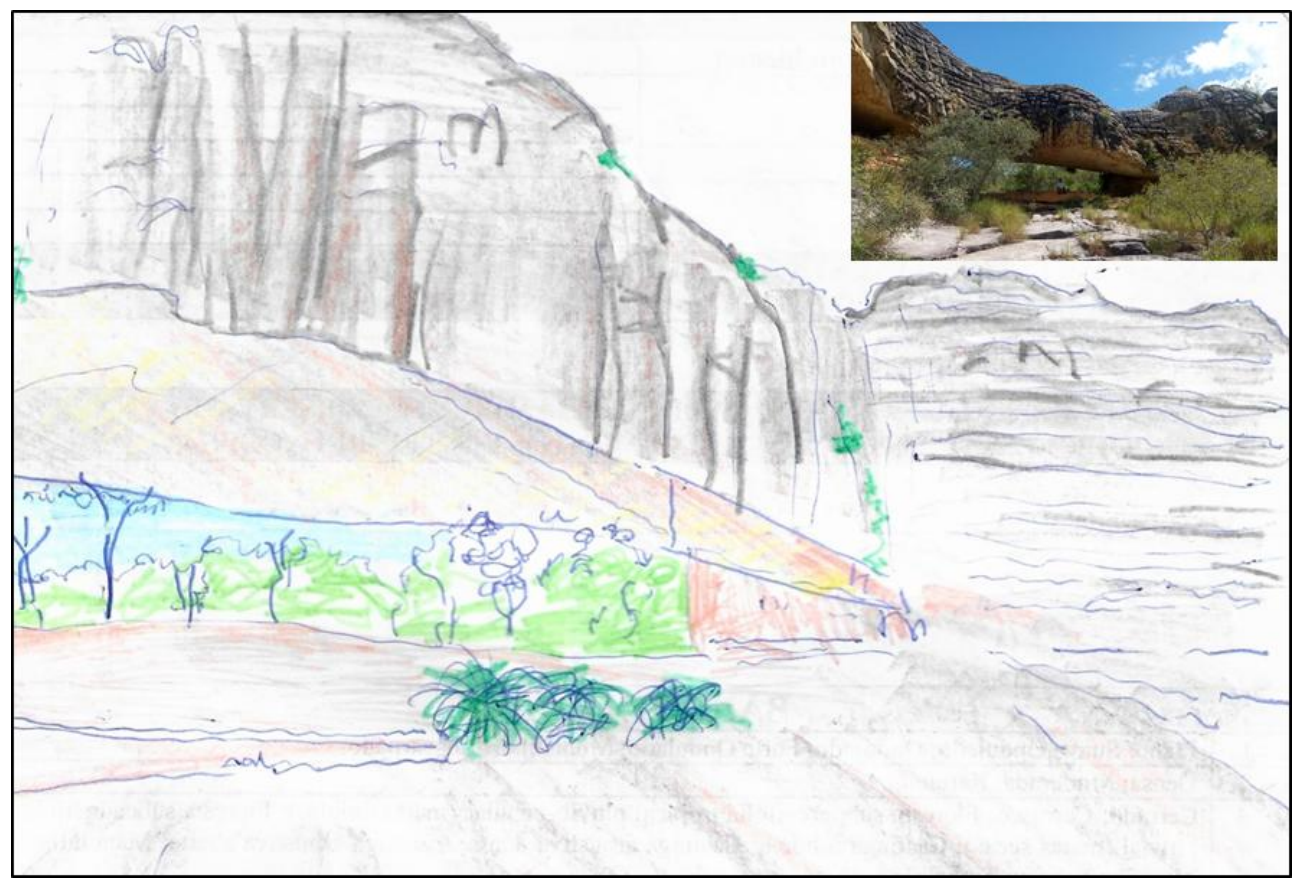

Figura 6: Representação do Geossítio "Biblioteca". Destaque para a existência de salão e sentido orientação da estratificação. Elaboração: F. Silva e E. T. V. Santos.

\subsection{Atividade 02: Os desenhos, as paisagem e a Geomorfologia e ambiente na porção da Bacia Hidrográfica do Rio Poti no município de Teresina/PI}

A segunda atividade de campo possui um total de 7 paradas investigativas ao longo da porção da Bacia Hidrográfica do Rio Poti no município de Teresina/PI. Cabe ressaltar que a área está inserida na Bacia Sedimentar do Parnaíba, e possui como sustentação geológica as Formações Pedra de Fogo, composta principalmente por arenitos e folhelhos, abrangendo a maior parte da área, e Piauí, na qual ocorrem argilitos e folhelhos. Esta última está localizada em trecho do canal do rio Poti.

No tocante ao aspecto geomorfológico, sustentado principalmente em levantamento realizado por Nunes, Silva e Aquino (2017), a discussão se deu inicialmente na compartimentação geomorfológica da área (4 unidades de relevo) e nas classes de declividade, sendo algumas vislumbradas em campo. Quanto às unidades de relevo, citam-se: Planícies e Terraços Fluviais; Superfícies Intensamente Retrabalhadas pela Drenagem com Morros Arredondados e Superfície Residual Recortada por Vales Encaixados, subdividida em Morros com Tendência ao Arredondamento Limitados por Relevo Escalonado e em Mesas com Topos Achatados Limitados por Escarpas, conforme classificação de Lima (2011).

Na primeira parada investigativa, na região Leste de Teresina, atentou-se para a caracterização do relevo do Parque João Mendes Olímpio de Melo, localizado na região Centro-Norte. As formas dominantes são de colina sob estrutura superficial composta de cascalheira clastosuportada e com predomínio de estabilidade morfodinâmica junto às Planícies e aos Terraços Fluviais, onde também se localiza a sétima parada, próximo ao bairro Bela Vista, em área de extração de material para a construção civil.

Já na $2^{\circ}, 3^{\circ}$ e $5^{\circ}$ paradas investigativas, ao longo do Rodoanel de Teresina, buscou-se a orientação da observação e da caracterização do relevo e do substrato geológico (incluso a discussão sobre vertentes e movimentos de massa) em áreas onde há "cortes" de morros, além da presença de pequenos canais fluviais. Nesses referidos pontos, a discussão foi condicionada ainda pelas feições erosivas (sulcos e ravinas) em vertentes (Figura 7), áreas de acumulação de sedimentos, planejamento ambiental, ordenamento territorial, bem como a disposição das camadas. Nestes pontos há a presença de morros com tendência ao arredondamento e recortadas por vales encaixados com presença de vertentes com declives intensos (Morros com Tendência ao Arredondamento Limitados por Relevo Escalonado). 


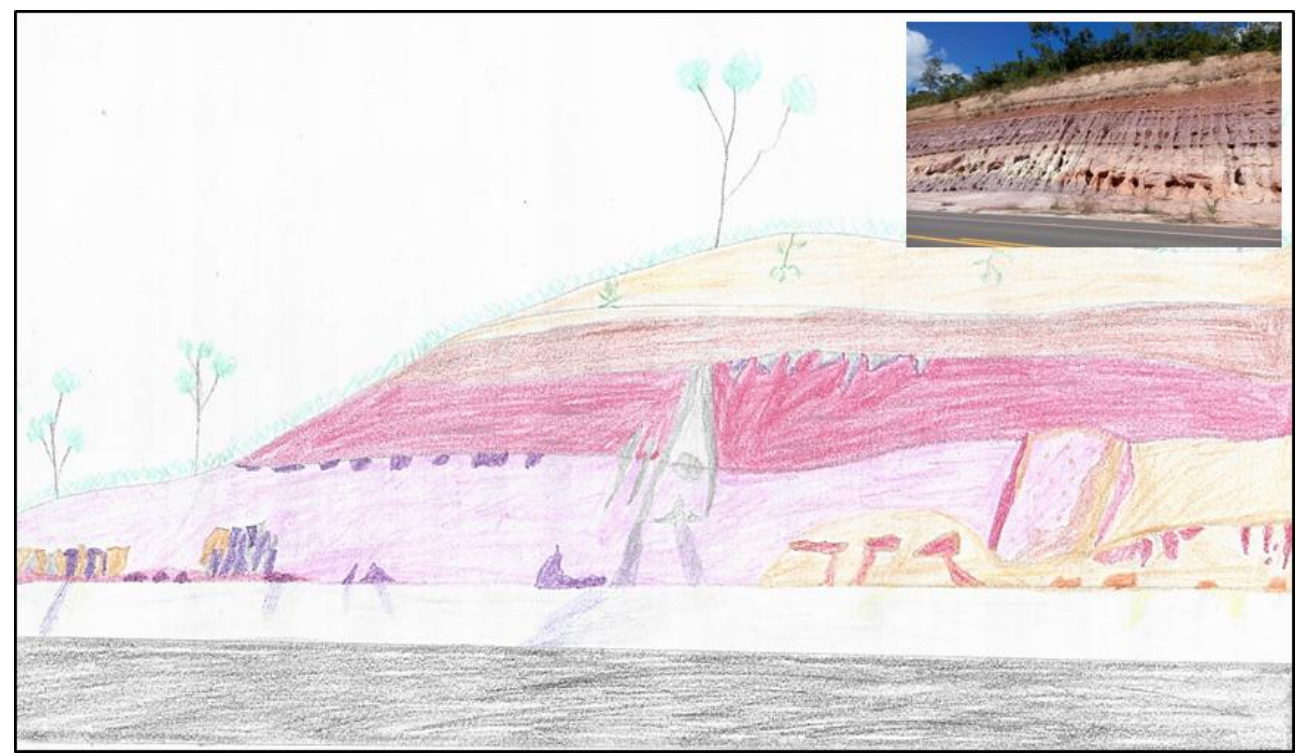

Figura 7: Representação de disposição de camadas/ horizontes e feições erosivas. Elaboração: P. G. B. Pinto; L. S. Santos; F. T. A. Cruz; F. C. J. O. Xavier; P. M. Silva e F. A. A. Oliveira.

$\mathrm{Na} 4^{\circ}$ parada, a discussão volta-se para o papel do rio Poti e suas funções de erosão, transporte e deposição de sedimentos, além da discussão sobre o relevo da zona Rural de Teresina e a utilização socioeconômica dos depósitos aluviais. Cabe reforçar que o trecho do rio pertence ao seu baixo curso e que há extensa presença de bancos de areia laterais e centrais, bem como cordões marginais convexos influenciando mudanças no canal fluvial e na velocidade hídrica além de característica meandrântica.

A discussão se deu em dois momentos: o primeiro, sobre a ponte do Rodoanel, visualizando trechos do canal, meandros e o relevo do entorno; a segunda, abaixo da ponte, foi favorecida pela proximidade com os bancos de areia. Nota-se, com as Figuras 7 e 8, a grande quantidade de elementos (como cores, linhas e volume) para evidenciar e ilustrar os fatos e processos geomorfológicos identificados e discutidos em campo, conciliando, assim, o conteúdo visto em sala de aula com o verificado fora dela.

Na $6^{\circ}$ parada, a discussão se deu no Aterro de Teresina (bairro Santo Antônio/Parque Juliana) sob visão socioambiental com abordagem da geomorfologia tecnogênica/antropogênica, face à existência de relevos artificiais, como verificado na Figura 9.

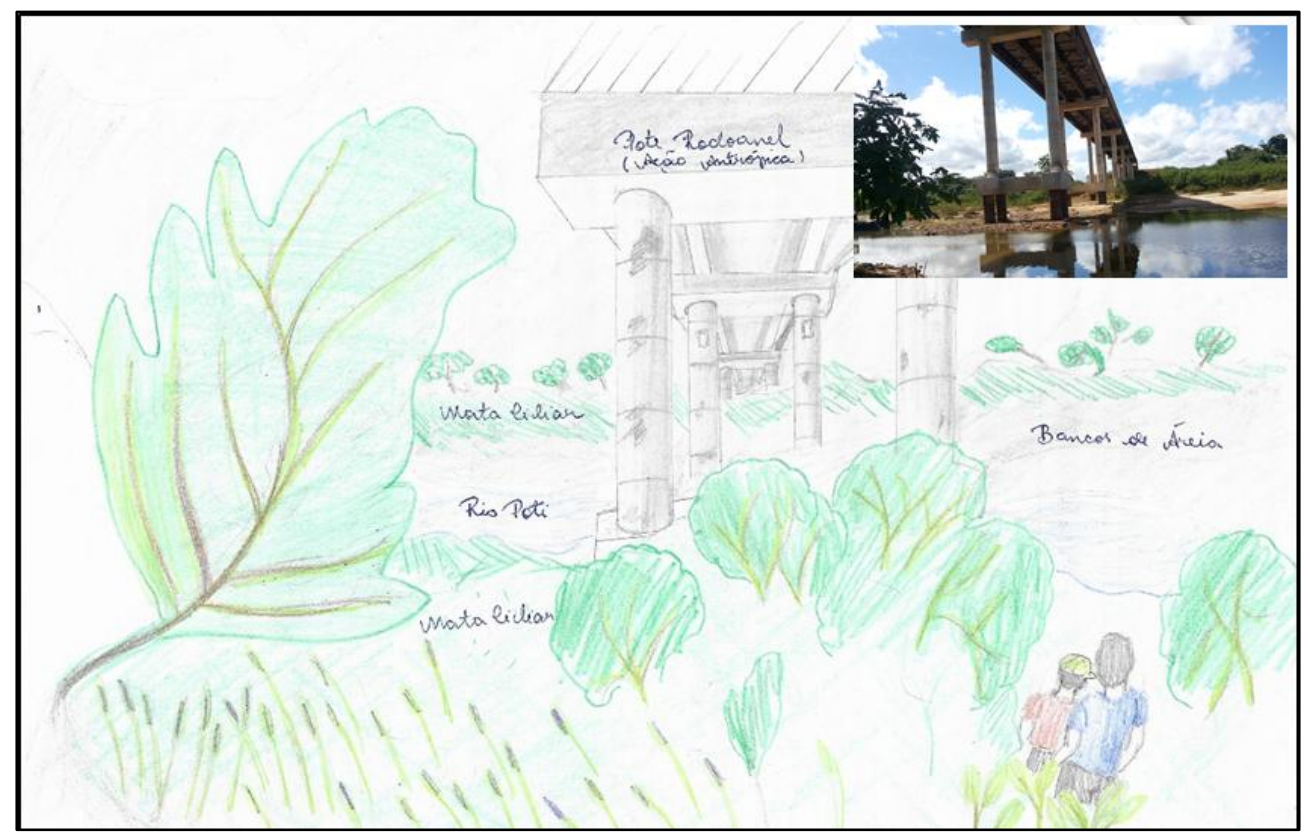

Figura 8: Representação da disposição/localização de bancos de areia no canal do rio Poti com identificação de resultados de obras de engenharia. Elaboração: A. C. A. Araujo; I. J. P. Sobral; J. S. Lopes; L. V. A. N. Costa e M. A. Sousa. 


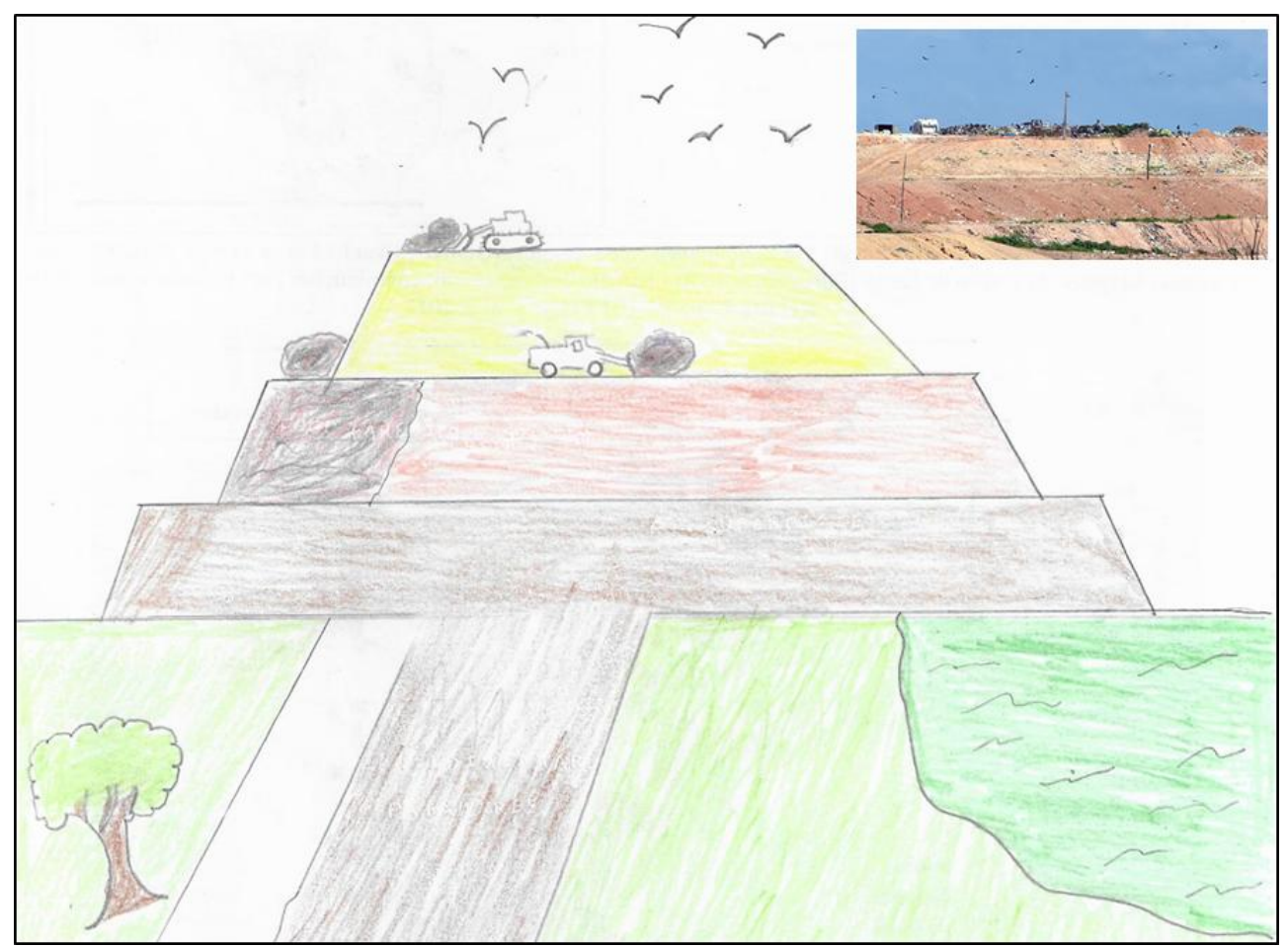

Figura 9: Representação da ação antrópica na gênese de relevos antropogênicos. Elaboração: I. O. Cordeiro Junior; M. C. P. Araujo; M. G. Sousa; R. S. Freitas; V. M. Nogueira.

Com a disposição de resíduos, verificou-se que as mudanças ocasionadas pela ação antrópica possibilitaram a alteração da morfodinâmica natural e, inclusive, na geração de relevos associados ao processamento dos resíduos, podendo auxiliar ainda na instabilidade do terreno, além da presença de erosão em sulcos. A maior expressão desta figura (com utilização de linhas, cores, volumes e escala), se comparada às demais, está justamente na utilização das técnicas para ilustrar e ratificar o papel do homem como um agente geomorfológico.

Os desenhos representam, assim, o ato de situar os alunos no mundo, dando-lhes condições de compreender tal realidade e possibilitar novos conhecimentos dentro do processo de ensino e aprendizagem na formação docente. O uso de recursos simples, como papel, lápis de cor, canetas e réguas, por mais simples que possam ser, são recursos de significativo valor para a construção de produtos pelos alunos.

\section{Considerações finais}

A capacidade de reprodução em desenhos de diferentes paisagens e ambientes, além de condicionar a questão do conhecimento científico, este no caso da ciência geográfica, possibilitou um real aprendizado, haja vista a potencialização da criatividade junto aos alunos, associando, assim, a visão, as mãos e a mente, individualizando cada desenho, bem como a criação de possibilidades de novas (re)leituras interpretativas.

Durante as atividades de campo foi perceptível, dentre outras coisas, o aprimoramento da observação com, em uma visão, identificar inúmeros processos associados ou não ao fator relevo. No processo de formação de professores de Geografia, tal como em outros cursos em que há atividades semelhantes à abordada neste trabalho, é salutar possibilitar o maior aprendizado possível nesse "sair da sala de aula" para o desenvolvimento de atividades que congreguem outras capacidades, como trabalho em grupo e estreitamento de laços entre os alunos e entre os alunos e os professores.

Ao elencar e discorrer sobre as atividades realizadas, obteve-se o principal objetivo, a aproximação entre os indivíduos (alunos) e o objeto de estudo (relevo) garantindo assim novas percepções. O desenho, nesse contexto, atinge e alcança função importante quanto aos processos e significados expressos.

Por fim, cabe mencionar ainda que, durante as duas atividades de campo, outros desenhos foram feitos com a mesma qualidade, sugerindo uma dinamização realizada por todos os alunos que participaram, o que serve de exemplos para outras vivências e reflexões. 


\section{Referências}

AB'SABER, A. N. Os domínios de natureza no Brasil: potencialidades paisagísticas. São Paulo: Ateliê Editorial, 2003.

ABREU, A. A. A Teoria Geomorfológica e sua edificação: análise crítica. Revista Brasileira de Geomorfologia, v. 4, n. 2, p. 51-67, 2003. DOI: http://dx.doi.org/10.20502/rbg.v4i2.24

AFONSO, A. Contribuição da Geografia Física e da Educação Ambiental na prática de professores de Geografia a partir do estudo de bacias hidrográficas em áreas urbanas. Revista Tamoios, v. 9, n. 1 p. 76-85, 2013. DOI: https://doi.org/10.12957/tamoios.2013.4874

AUSUBEL, D. P. A aprendizagem significativa: a teoria de David Ausubel. São Paulo: Moraes, 1982.

ARAÚJO, E. C. D.; TROLEIS, A. L. Recursos didáticos, formação inicial docente e o processo de ensino e aprendizagem no Pibid geografia UFRN. Confins, v. 25. 2015. DOI: https://doi.org/10.4000/confins.10605

BEZERRA, J. B.; MELO, F. P. Os dilemas da tríade geografia física, humana e disciplinas pedagógicas na formação do licenciado em geografia. In: COLÓQUIO INTERNACIONAL DE EDUCAÇÃO GEOGRÁFICA, 1., 2018, Maceió. Anais... Maceió, 2018.

BIGARELLA, J. J.; et al. Estrutura e origem das paisagens tropicais e subtropicais. Florianópolis: EdUFSC, 1994.

CABANELLAS, I. Dibujo. Espanha: Magisterio Español, 1976.

CAMPOS, M. C. A formação do professor de geografia: a difícil construção do saber/fazer docente. Geosaberes, v. 3, n. 6, p. 3-15, 2012.

CASTELLAR, S. M. V. O Ensino das temáticas físico-naturais e a formação inicial de professores. In: MORAIS, E. M. B.; ALVES, A. O.; ASCENÇÃO, V. O. R. (Orgs). As contribuições da Geografia Física para o ensino da geografia escolar. Goiânia: C\&A Alfa Comunicação, 2018.

CAVALCANTI, A. P. B. Abordagem metodológica do trabalho de campo como prática pedagógica em Geografia. Geografia, Ensino \& Pesquisa. v. 15, n. 2, p. 265-175, 2011. DOI: https://doi.org/10.5902/223649947371

CLOPÉS; J. M. P.; SERRANO, M. B. La expresión gráfica del territorio mediante paisajes lineales. Cuadernos Geográficos, v. 51, p. 78-85, 2012.

CONTI, J. B. Geografia e Paisagem. Ciência e Natura, v. 36, p. 239-245, 2014. DOI: http://dx.doi.org/10.5902/2179460X13218

CORTIZO, T. L.; FERREIRA, E. S.; FARIAS, M. L. S. O.Saber profissional docente: autoridade ao espelho da autonomia na escola contemporânea. Educação Unisinos, v. 21, n. 1, p. 60-69, 2017. DOI: https://doi.org/10.4013/edu.2017.211.11346

COURTOT, R. Los dibujos de trabajo de campo en la Escuela francesa de Geografía (Paul Vidal de La Blache y Pierre Deffontaines). Treballs de la Societat Catalana de Geografia, v. 70, p. 85-100,2010.

CRUZ, F. M. L.; AGUIAR, M. C. C. Reflexos dos professores-formadores na identidade profissional de docentes universitários. Educação e Cultura Contemporânea, v. 11, n. 24, p. 92-110, 2014.

FIORI, S. R. Técnicas de desenho e elaboração de perfis. In: VENTURI, L. A. B. (Org). Geografia: práticas de campo, laboratório e sala de aula. São Paulo: Sarandi, 2011.

GATTI, B. A. Didática e formação de professores: provocações. Cadernos de Pesquisa, v. 47, n. 166, p. 1150-1164, 2017. DOI: https://doi.org/10.1590/198053144349. 
IBGE. INSTITUTO BRASILEIRO DE GEOGRAFIA E ESTATÍSTICA. Manual técnico de Geomorfologia. Rio de Janeiro: IBGE, 2009.

IBGE. INSTITUTO BRASILEIRO DE GEOGRAFIA E ESTATÍSTICA. Mapa geomorfológico do Brasil (escala 1:5.000.000). Rio de Janeiro, 1995.

JOHNSON, J. K.; REYNOLDS, S. J. Concept Sketches-Using Student-and Instructor-generated, Annotated Sketches for Learning, Teaching, and Assessment in Geology Courses. Journal of Geoscience Education, v. 53, n. 1. p. 85-95, 2005. DOI: 10.5408/1089-9995-53.1.85

KAERCHER, N. A.; BOHRER, M. O menino irreflexivo e a demissão subjetiva da docência: razão e emoção para manter viva a chama do aprender a ensinar geografia com nossos alunos. Revista Presença Geográfica, v. 5, n. 2. p. 111-121. 2018. DOI: https://doi.org/10.36026/rpgeo.v5i2.3850

LIMA, I. M. M. F. O relevo de Teresina, PI: compartimentação e dinâmica atual. In: ENCONTRO NACIONAL DA ASSOCIAÇÃO NACIONAL DE PÓS-GRADUAÇÃO E PESQUISA EM GEOGRAFIA, 9., Goiânia, 2011. Anais... Goiânia, 2011.

LOPES, C. S.; PONTUSCHKA, N. N. Estudo do Meio: teoria e prática. Geografia (Londrina), v. 18, n. 2, p. 173-191, 2009. DOI: http://dx.doi.org/10.5433/2447-1747.2009v18n2p173

LOPES, C. S.; PONTUSCHKA, N. N. O conhecimento pedagógico do conteúdo na prática profissional de professores de geografia. GEOUSP: espaço e tempo, v. 19, n. 1, p. 76-92, 2015. DOI: 10.11606/issn.21790892.geousp.2015.79809.

LOPES, L. S. O. Geoconservação e Geoturismo no Parque Nacional de Sete Cidades, Piaú́. Teresina, 2011. 123f. Dissertação (Mestrado em Desenvolvimento e Meio Ambiente) - Universidade Federal do Piauí, 2011.

MORAIS, E. M. B.; MORAES, L. B. (Orgs.) Formação de professores: conteúdos e metodologias no ensino de Geografia. Goiânia: Vieira, 2010.

MORAIS, E. M. B. As temáticas físico-naturais nos livros didáticos e no ensino de geografia. Revista Brasileira de Educação em Geografia, v. 4, n. 8, p. 175-194, 2014.

MOURA-FÉ, M. M. Análise das unidades geomorfológicas da Ibiapaba Setentrional (Noroeste do estado do Ceará, Brasil). Caminhos de Geografia, v. 18, n. 63, p. 240-266, 2017. DOI: https://doi.org/10.14393/RCG186311

NEVES, C. E.; SALINAS, E. A Paisagem na Geografia Física Integrada: impressões iniciais sobre sua pesquisa no Brasil entre 2006 e 2016. Revista do Departamento de Geografia, v. esp., p. 124-137, 2017. DOI: https://doi.org/10.11606/rdg.v0ispe.132757

NOVAK, J. D.; GOWIN, D. B. Aprender a aprender. Lisboa: Plátano Edições Técnicas, 1999.

NUNES, H. K. B.; SILVA, J. F. A.; AQUINO, C. M. S. Aspectos geológicos e geomorfológicos da porção da Bacia Hidrográfica do Rio Poti em Teresina/Piauí: contribuições para o planejamento ambiental. Equador, v. 6, n. 2, p. 75-89, 2017.

NUNES, H. K. B.; SOUSA, S. R. C. T.; VIANA, A. I. G. Atividades de campo e formação de professores de Geografia em uma universidade do Piauí. Geosaberes, v. 9, n. 19, p. 1-14, 2018. DOI: https://doi.org/10.26895/geosaberes.v9i19.660

NUNES, J. O. R. Reflexões sobre as teorias geomorfológicas e sua relação com a geografia. Geografia Em Atos (Online), v. 4, n. 11, p. 125-133, 2019. DOI: https://doi.org/10.35416/geoatos.v4i11.6501

PARÉ, G. Investigating Information Systems with Positivist Case Research. Communications of the Association for Information Systems, v. 13, n. 18, p. 233-265, 2004. DOI: https://doi.org/10.17705/1CAIS.01318 
PASSOS, M. M. Paisagem e Meio Ambiente (Noroeste do Paraná). Maringá: Eduem, 2013.

PERRENOUD, P. 10 Novas competências para ensinar. Porto Alegre: Artes Médicas Sul, 2000.

PERRENOUD, P. Construir as competências desde a escola. Porto Alegre: Artes Médicas Sul, 1999.

PRESS, E. et al. Para entender a Terra. Porto Alegre: Bookman, 2006.

SANTANA, S. S.; BRAGA, M. C. B. O conceito de professor reflexivo na prática docente em geografia. Revista de Ensino de Geografia, v. 4, n. 7, p. 39-60, 2013.

SANTOS, F. A. Análise Integrada da Paisagem em Trabalho de Campo no Parque Nacional de Sete Cidades (PI). Geografia (Londrina) v. 27. n. 11, p. 103-119, 2018. DOI: http://dx.doi.org/10.5433/24471747.2018v27n1p103

SENAI. Serviço Nacional de Aprendizagem Industrial/Divisão de Material Didático. Desenho técnico e artístico. São Paulo: SENAI, 1984.

SOUZA, C. J. O. Ensino de Geomorfologia: desafios na formação inicial. Revista de Geografia (Recife), v. 35, n. 4, p. 288-308, 2018.

SOUZA, C. J. O.; VALADÃO, R. C. Habilidades e competências no pensar e fazer geomorfologia: proposta para a formação em geografia. GEOUSP: Espaço e Tempo, v. 19, n. 1, p. 93-108, 2015. DOI: https://doi.org/10.11606/issn.2179-0892.geousp.2015.99768

SUERTEGARAY, D. M. A. Geografia Física e Geomorfologia: uma releitura. Porto Alegre: Compasso, 2018.

VENTURI, L. A. B. A técnica e a observação na pesquisa. In: VENTURI, L. A. B. (Org). Geografia: práticas de campo, laboratório e sala de aula. São Paulo: Sarandi, 2011.

VENTURI, L. A. B. Paisagem geográfica: muito além do nosso campo de visão. Confins (Paris), n. 38, 2018. DOI: https://doi.org/10.4000/confins. 16282

YIN, R. K. Estudo de caso: planejamento e métodos. Porto Alegre: Bookman, 2010.

(1) (\$) (2)

BY

NC

Este artigo é distribuído nos termos e condições do Creative Commons Attributions/AtribuiçãoNãoComercial-CompartilhaIgual (CC BY-NC-SA). 